Maria Mannone

Department of Mathematics and Informatics

University of Palermo

Italy

\section{Dimitri Papageorgiou}

Aristotle University of Thessaloniki

Greece
UDC 781

doi: $10.5937 / \mathrm{ZbAkU} 2008137 \mathrm{M}$

Professional paper

\title{
Gestural Similarity, Mathematics, Psychology: Hints from a First Experiment and some Applications between Pedagogy and Research
}

\begin{abstract}
Can music and drawings be thought of as the results of physical gestures, and thus be compared? In this paper we summarize the conjecture of "gestural similarity" developed in the framework of the mathematical theory of musical gestures. Then, we outline the history of an experiment involving mathematics, music, drawing, and psychology, aiming to evaluate the cognitive relevance of the conjecture. A simple visual form and a short homophonic musical sequence can be considered ,similar“ if they can be thought of as produced by the same movements. Participants in an experiment were asked to assess the degree of similarity between given music examples and simple visuals (three visuals for each sound stimulus). Results were analyzed and confirmed the theoretical expectations. In addition, we describe some creative applications of this conjecture, including pedagogical and creative developments. In particular, we describe the music derived from a natural form, the essential structure of an ammonite, and the illusion of a „mathematical ocean“ with sounds and images. We discuss challenges of these techniques and the characteristics of spectrograms in relation with gestural similarity.
\end{abstract}

Keywords: musical articulation, movement, gesture, drawing, perception.

\section{Introduction}

Why is the feeling of dizziness in the opening scene of Hitchcock's movie Vertigo so well represented by the spiraling visuals and a spiral-like musical theme? Why does the repeated staccatissimo screech of the strings make such a suitable accompaniment to the relentless stabbing of the knife in the enthralling 'shower scene' of Hitchcock's Psycho? It seems that some expressions, visual or auditory, appear so ,similar" to one another that they can be considered as the result of the same movement. 
There are studies that could support this idea. According to Rosenblum et al. (2016), there are centers in the brain that receive sensory stimuli from various sensory systems and process them as singular pieces of information to create a complete picture. If a sense is damaged, the corresponding information is reconstructed in the brain from other senses. Other scholars proposed the concept of ,audiovisual object" to stress the integration between specific sensory stimuli as a unique piece of information (Kubovy \& Schutz, 2010).

Regarding music, Truslit asked listeners to draw lines according to some music. Then, other musicians improvised music according to those lines: results showed strong analogies between initial and final music (Repp, 1992). Zbikowski (2017) found gestural analogies between performers' movements and program music suggestions. In an experiment, participants drew lines and made gestures according to vocal lines from different musical genres (Kelkar \& Jensenius, 2018). In another experiment (after and independent from ours), shapes were converted into spectrograms and were subsequently recognized as being derived from the initial visuals (Engeln \& Groh, 2019, 2020).

Several scholars investigated analogies between images, movement, and music. It has been analyzed how dancers can gesturally render abstract concepts such as „fragility" and „lightness", and if and how the audience can recognize these concepts (Niewiadomski et al., 2018). Leech-Wilkinson (2017) focus on "shape“ and shape-related metaphors, describing dynamics, pitch contour, texture, and so on. While describing musical features, musicians often use gestures to draw imaginary shapes in the air - this might be compared with the so-called ,air playing" (Godøy et al., 2006). Body motion in playing or dancing can be perceived in terms of shapes, and spectrograms visualize some sound "shapes“. Proper measurements of gestures are not trivial. As pointed out by Godøy and Leman (2010), spectrograms do not give us (precise) information about where a gesture starts or ends. To quantitatively investigate gestures and analyze gesture perception, Godøy and Leman (2010) focus on motion caption technologies as well as on theoretical apparati. ${ }^{1}$ Leman distinguishes between gestures accompanying musical performance and sound-producing gestures.

Here, we implicitly consider gestures producing sound or needed to expressively shape sound-e.g., while thinking of a caressing gesture, a pianist can modify his/her gesture to achieve a soft sound that can be perceived by the listener as a caressinglike gesture. Such a movement can be defined as ,sound-facilitating“ in the framework proposed by Jensenius et al. (2010), who distinguished between sound-producing, sound-facilitating, and communicative gestures. Expression and physical movements can thus be intertwined. This is why we can be „moved“ by music, as noticed by Borgo (2011) in his review of Leman (2008), who sees musical communication as based on „the role of the human body as a natural mediator of music“.

1 The word „apparatus“can have the plural as „apparati“as in Latin, or „apparatuses“ by considering English rules. 
According to Godøy and Leman (2010), it is hard to unambiguously retrieve gestural information from sound: are there true analogies between energy and loudness increase or between rising movement and rising pitch contour? In support of these analogies, we can observe that a singer who sings higher notes will feel them ,in the head"; more energy is needed to increase loudness while playing (also slightly changing timbre). These specific examples appear to be rooted in biology and cross-modal correspondences and are also corroborated by research in human cognition (Spence, 2011) with results that only vary slightly across countries. While studying music-togesture, Eitan and Granot (2006) ran listening-cognition experiments to investigate cross-modal correspondences such as between pitch patterns and ascending-descending displacements. Similarities of cross-modal correspondences between gesture-imagesound have also been shown by people blind from birth (Eitan et al., 2012). Interestingly, the Kaluli people of New Guinea use the metaphor of a waterfall to describe descending melodic sequences, whereas they do not have an equivalent metaphor to indicate rising pitches (Zbikowski, 2017).

If we see our world as a collection of pulses and movements, music can represent a privileged way to analyze our interaction with it. Kozak (2020, chap. 3) discusses listeners' capabilities to synchronize their movements with pulses and events scattered across time, showing ,intercorporeality“ and involvement with the surrounding world. Physical (and mental) gestures in music performance can be demanding, but they are rewarding as a motivational activity. This is what Leman (2016) defines as „empowerment".

In summary, what is the relationship between physical gestures and images? Images can be seen as the trace of physical gestures. Suitable physical gestures generate music. Thus, we might compare images and music that are rooted in the same (or very close) physical gestures. Of course, there is not a one-to-one correspondence between music and images. In fact, physical gestures (which have a proprioceptive element) are not the same as visuals. Visual representations and musical sequences can be seen as potentially analogous to physical gestures, but they are not necessarily so; this is a way to investigate them. When we analyze a visual form, we can only imperfectly go back to generator gestures, and the same gesture can be recognized in a variety of images (and musical sequences). However, there is an „equivalence class“ of possible images (and musical sequences) associated with the same gesture. Thus, we abandon the idea of „equality“ in favor of the idea of „equivalency“ (as a category theorist would say, "up to an isomorphism').

A conjecture of ,gestural similarity“ (GSC) has been proposed (Mannone, 2018) while applying the mathematical definition of gesture (Mazzola \& Andreatta, 2007; Figure 1) to orchestral instruments. The mathematical description of musical gestures is inspiring new theoretical studies (Arias-Valero \& Luis-Puebla, 2020; Clark, 2020; Jedrzejewski, 2019; Arias, 2018). 

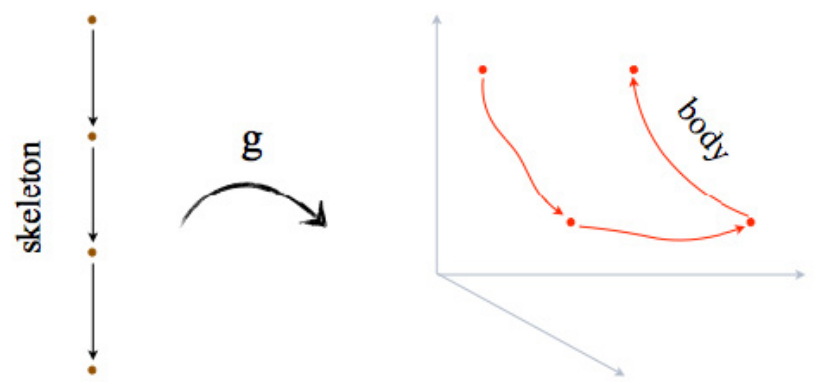

Figure 1. Formal definition of a gesture as a mapping from a diagram within a topological space (an abstract space), left, to a continuous curve in the spacetime or the space of parameters, right. $^{2}$

Is GSC cognitive, relevant, and falsifiable? What creative applications could it have? Here, we describe the development of an initial experiment to validate GSC, related to a collaborative research project of Maria Mannone with Tom Collins, Dimitri Papageorgiou, and Delilah Hsu. Then, we discuss some creative applications.

\section{Some concepts from the theoretical approach}

We can make assessments of similarity between visual and auditory domains considering the forms themselves and the movements that produce them.

According to GSC, two musical gestures have a high degree of gestural similarity if:

1. Their spectrograms have similar characteristics (e.g., they both represent a forte dynamic or a staccato articulation);

2. Their gestural generators have similar characteristics (e.g., they both require an increase of hand pressure or airstream pressure for the forte, or they both have detached movements for the staccato, be it of the pianist's hands or the flutist's airstream or leap movements.)

This condition is close to fuzzy thinking and it is very general. It requires analysis of movements in the parameter space of each instrument. For example, a stroke on a flute does not make a ,forte" flute sound as it would on the timpani, but instead it breaks the flute! Learning how to play a musical instrument also includes learning which specific gestures are needed for each instrument and what is the parameter space specific for each instrument; e.g., the flute parameter space includes airstream characteristics, leap articulation, and fingering (Figure 2).

GSC has been extended to the relationship between music and image. A simple musical sequence and a simple visual form can be characterized as similar if they appear to be generated by the same physical movement. E.g., a detached gesture can produce a staccato musical sequence as well as a collection of dots on a piece of paper. 2 Image adapted from (Mazzola and Andreatta, 2007). 
Vice versa, smooth and uninterrupted movements can produce a waved line as well as a legato sound (Figure 3).

Details are given in a paper that uses the mathematical language of categories (Mannone, 2018). Category theory uses diagrams with points, arrows, and arrows between arrows: it formalizes the idea of transformation between transformations (Mac Lane, 1978). It is suitable to describe metaphors and blurred analogies. It couldparadoxically_seem not very mathematical to non-experts, but it allows us to model relationships in an abstract and general way. Figure 4 shows the conjecture of similarity between images and sounds by using a triangular diagram. The diagram is said to be „commutative“ if the paths gesture-image-sound or gesture-sound can be perfectly interchanged. In reality, there is some degree of interchangeability. Let $f$ be the arrow from gesture to image, $g$ the arrow from image to sound, and $h$ the arrow from gesture to sound. Commutativity means that " $g$ composed with $f=h$ ". In formulas, $g f=h$. That is, the commutator (a mathematical object also used in physics) is $[g f, h]=g f h-h g f=0$. In reality, this quantity is not 0 if it commutes and 1 if it does not commute, but a value $\mathrm{d}$ between 0 and $1:[g f, h]=d$, with $d=$ degree of gestural similarity.

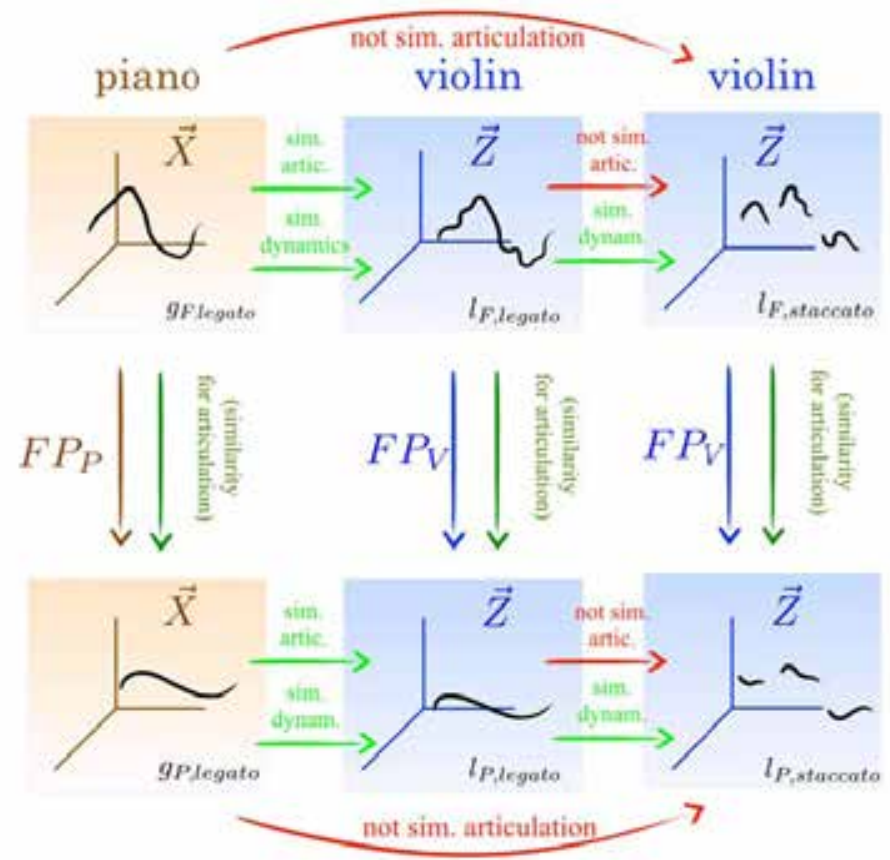

Figure 2. Abstract graphs of gestural similarities and non-similarities for violin and piano movements. $\mathrm{X}$ and $\mathrm{Z}$ with the arrows indicate the space of curves connecting performance parameters. ${ }^{3}$

3 Image from: Mannone, 2018. 
Explanation: A forte, legato on piano is similar to the forte, legato on violin regarding both dynamics and articulation, but it has a different articulation from a forte, staccato. These variations can be modeled through mathematical concepts such as homotopy transformations (deformations without cuts or gluing; e.g., legato-legato here) and non-homotopy transformations (e.g., legato-staccato here). The lines within diagrams represent the movement within each parameter space, different for each instrument (e.g., hands'positions, pressure and time for the pianist, bow's movements, pressure, left-hand position and time for the violinist). The lines refers to the actual contact with the instrument. In fact, in the case of staccato, there are some cuts, corresponding to the distance of performer's hands or bow from the keyboard or the violin's strings, respectively. The graphs are represented within 3-dimensional spaces. However, the general representation involves $\mathrm{N}$ dimensions according to the $\mathrm{N}$ parameters considered for each instrument.
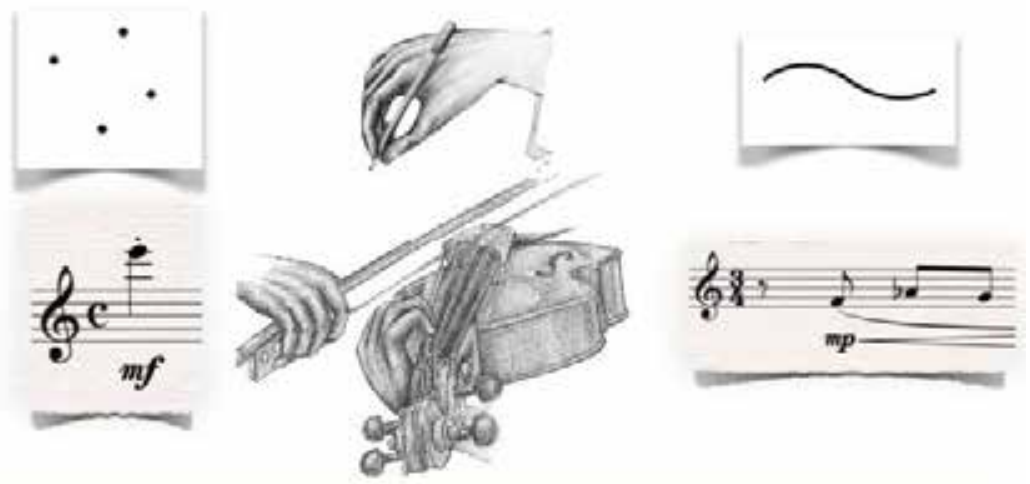

Figure 3. Gestural similarity between hand and pencil drawing and simple bowing movements. ${ }^{4}$

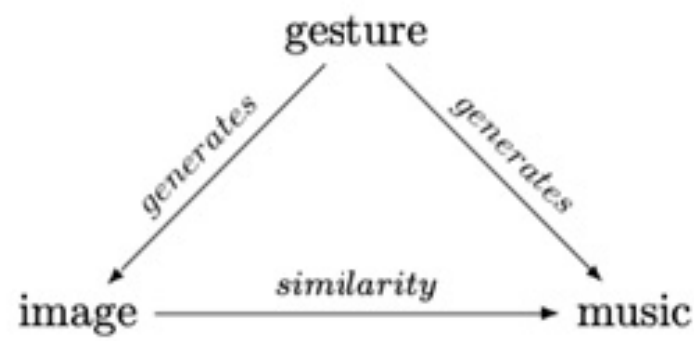

Figure 4. Triangular diagram depicting the conjecture of gestural similarity between music and images.

$4 \quad$ Drawing by Maria Mannone. 


\section{Experiment outline}

The collaboration between M. M., T. C., and D. P. started with the Women in Music Information Retrieval project (WiMIR). In Spring 2017, M. M. was completing her dissertation at the University of Minnesota, where she connected her former studies on music from tridimensional images (Mannone, 2011) to mathematical gestures. During WiMIR, she was mentored by T. C. in music cognition and D. P. in compositional applications of math/music. After an initial brainstorming, the focus narrowed to $\mathrm{M}$. M.'s definition of gestural similarity, and she had the idea of organizing an experiment. The experiment was run in 2018 by T. C. for his students at Lehigh University in the United States, where he was teaching at that time. The activity was pedagogical because it had been proposed to students in order to teach them how to do research. But it was also a true research project in itself because its results were unknown.

M. M. prepared the visuals and the sound samples in Sibelius; T. C. enhanced sound quality and prepared the online interface for the experiment. Sounds were associated to visual shapes according to GSC. Figure 5 shows shapes and their best music associations. In total, 84 musical examples were prepared, with varying speed, pitch range, and instrumentation. The number 84 comes from 2 tempi (fast or slow tempo) x 3 pitch ranges (high, medium, or low) x 2 instruments (pairs picked up from violin, flute, or piano timbres) $\times 7$ forms. The forms were: angled straight lines, dots, ellipses, half cycle, one cycle, squiggly line, and straight line.

The hypothesis included the independence of the outcomes from the parameters' speed, pitch, range, and instrumentation. All musical sequences were homophonic.

Participants listened each time to a short musical sequence while looking at three visual examples. After listening to each musical sequence, participants were asked to score (between 0 to 100) the degree of similarity to the auditory stimulus for each of the three images. Experiment outcomes were collected and analyzed via ANOVA test by T. C.

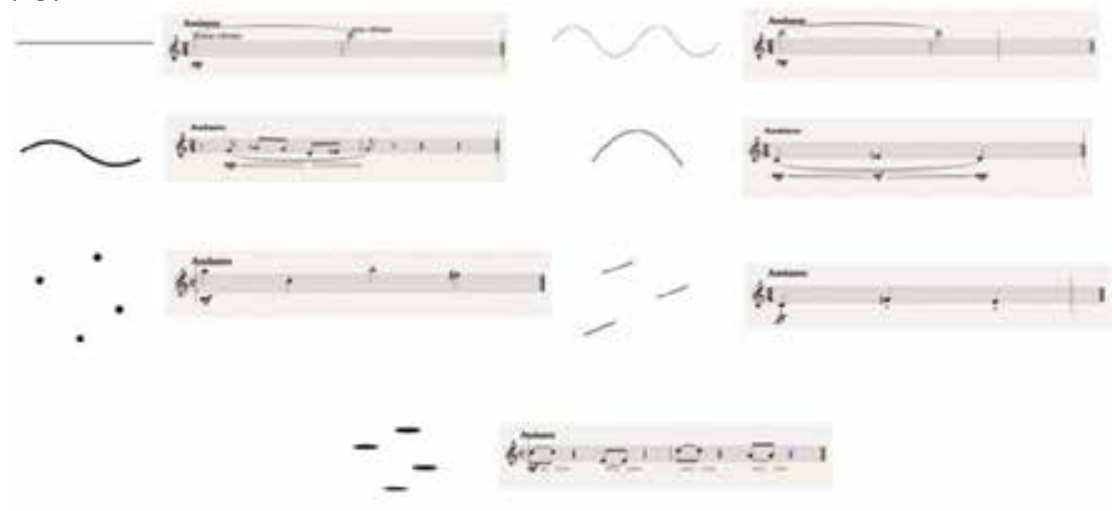

Figure 5. Best associations between visual shapes and musical sequences for the experiment 
The results show concordance with theoretical expectations, an independence from tempo, a slight dependence for timbre, and a better agreement for some shapes than others. As probably expected, some of the agreements acknowledged the association between a straight line and a non-vibrato constant sound; dots and soft staccato; and, angled short segments and staccatissimo.

The experiment was presented as a poster during the WiMIR session in Paris on September 2018 (Figure 6). The poster was printed and displayed, and it has been described via Skype.

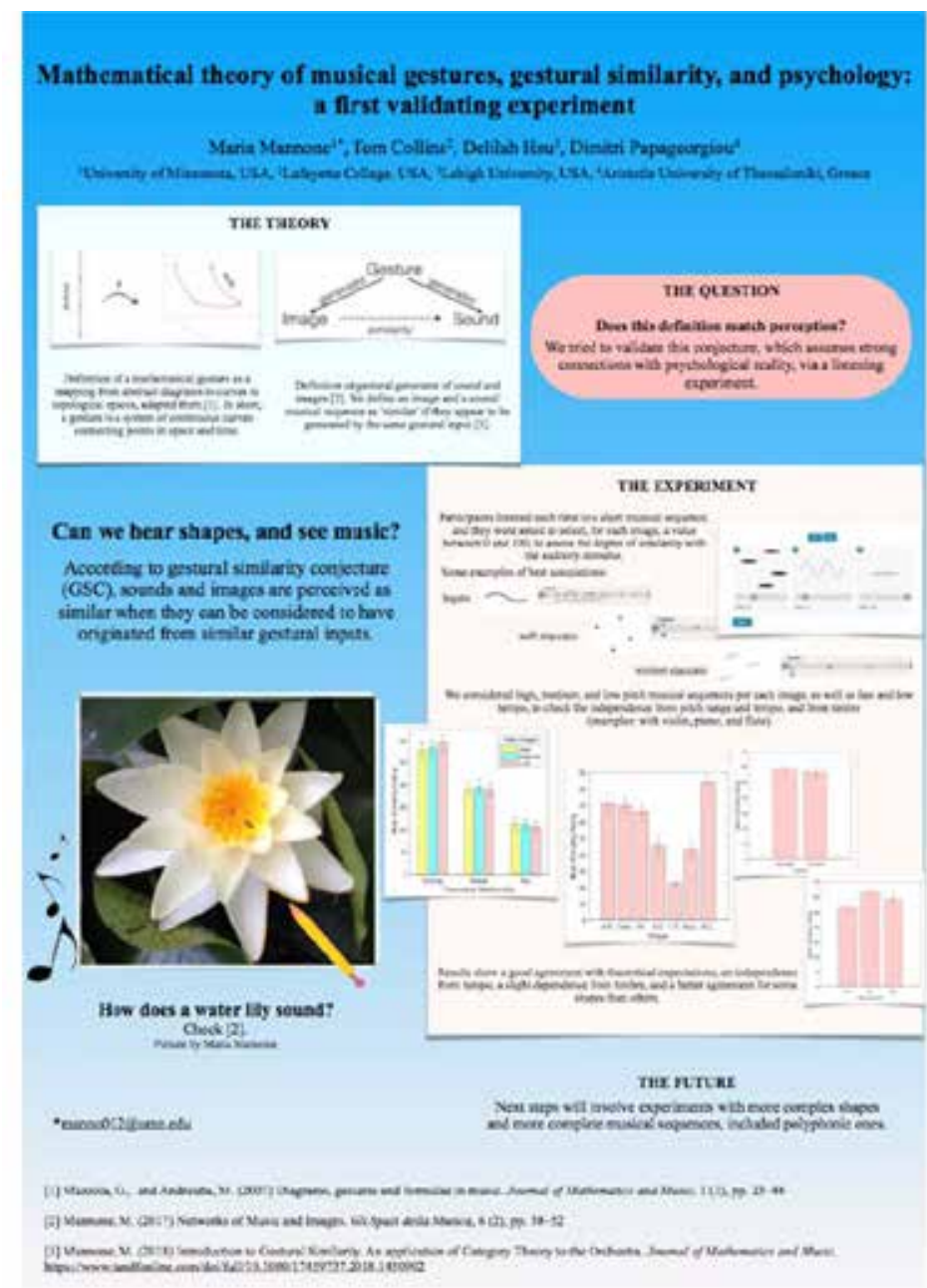

Figure 6. The poster presented during the WiMIR session at the end of ISMIR Paris 2018 Conference ${ }^{5}$

5 Water lily picture and overall graphics by Maria Mannone. 
Explanation: The „Theory“ with the mathematical definition of musical gesture and the GSC led to a research „Question" and to the „Experiment." The pink box contains an image from the online experimental setup, some of the image/sound expected associations, and the graphs of students' answers. These graphs, made by T. C., show the results. There is a good agreement between similarity ratings and theoretical expectations. Similarity ratings according to the visual shape variations are very close to the expectations. Also, similarity ratings' variations according to instrument change and tempo variations are negligible, as expected.

\section{Music, spirals, and ammonites}

Detecting gestural similarity while looking at spectrograms as opposed to visual images is not very easy. In some cases, we cannot directly compare a spectrogram with the structure of an image as scanned from left to right as a score. If we hand-draw a spiral, e.g., when sketching the structure of an ammonite or of a nautilus, our hand goes up and down and left and right (Mannone, 2019). Thus, the music derived from this should give us the feeling of an ascending-descending and enlarging-shrinking movement. When observing the spectrogram of such a piece of music, we would not see a shell, but probably a damped sinusoid-like shape, or a sequence of rising-falling steps becoming larger in time and in pitch. Figure 7 shows a transition from the spirallike form of an ammonite toward a musical sequence, played on the piano and analyzed with spectrograms. From the top left to the bottom right, we see:

- the drawing of an ammonite;

- its simplified modeling as a 3D shape;

- its modeling as a 2-D line;

- a musical theme derived from a selection of its points;

- the spectrograms of the theme's piano performance.

See (Mannone, 2019) for details about the composition technique (from Archimedean spiral's samplings). This sequence constituted the theme of the piece Perfect Shapes in the Prehistoric Sea, see Web Sources.

The arrows in the 2D-model indicate the direction representing time flowing. It is like moving along the spiral, drawing it, building up the image according to that time direction. Such a direction is what gives shape to the musical sequence, whose pitches are a mapping into sound of a selection of points of the 2D-model. 

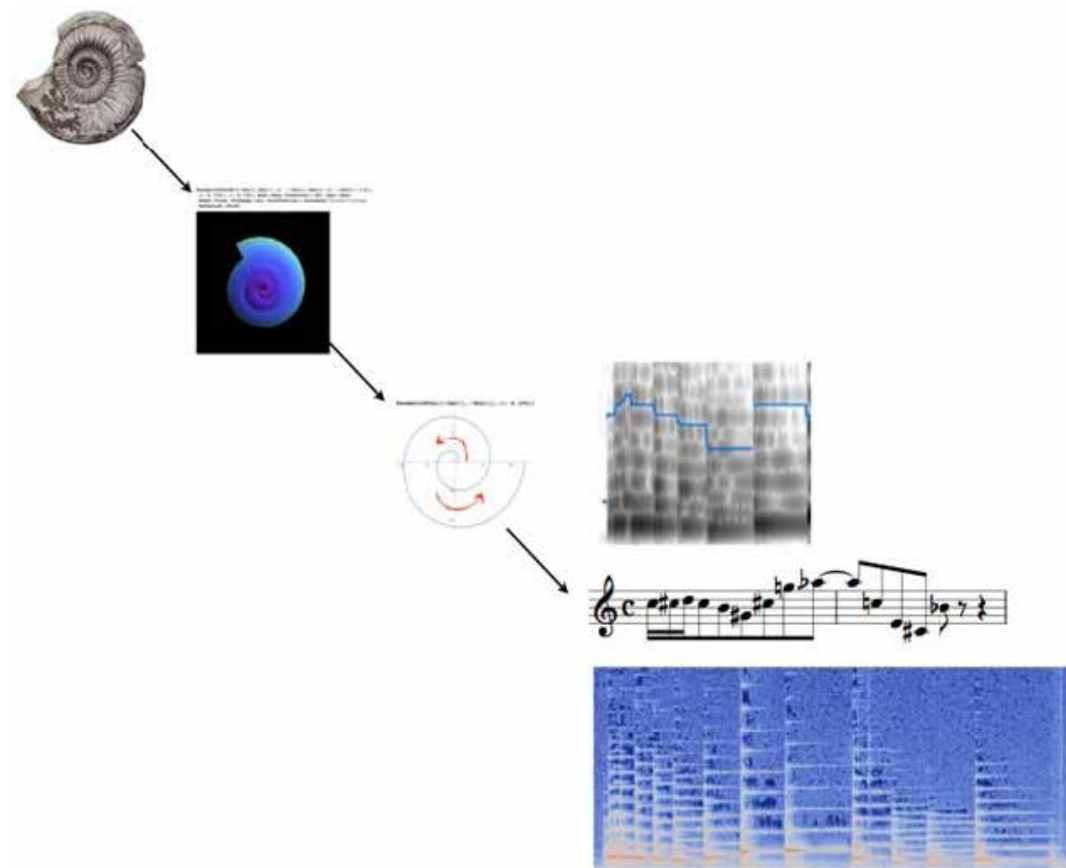

Figure 7. Comparison between a special form, a short musical sequence derived from it, and the shape of its spectrogram. ${ }^{6}$

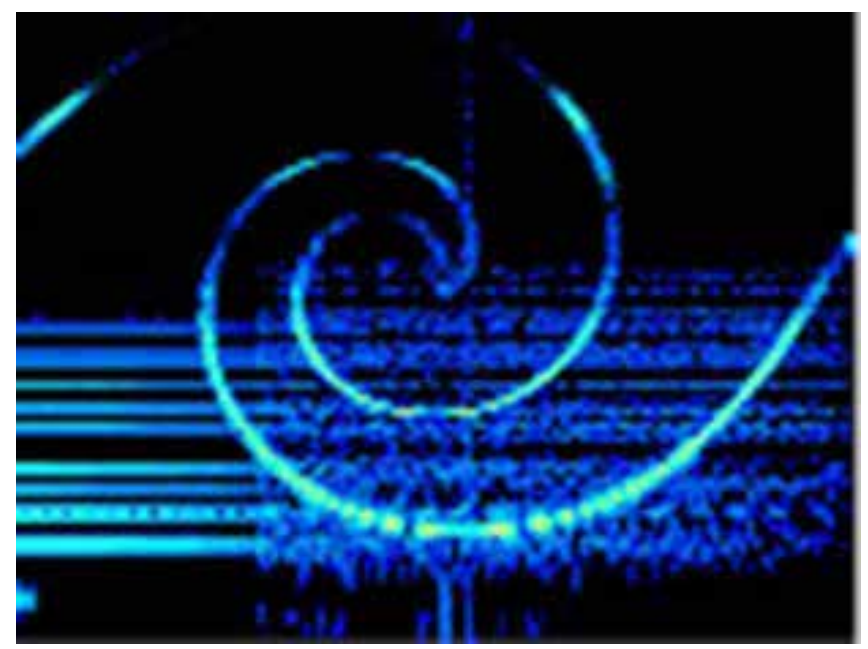

Figure 8. A spiral-like drawing within a spectrogram. This spectrogram has been made by J. Niinisalo (2017), analyzing the track \#1 of Aphex Twin's album „Windowlicker".

6 Drawing, music, and analysis by M. Mannone (2019). 
Explanation: This image only partially verifies gestural similarity: in fact, the time is flowing from left to right, not along the spiral form. Thus, the music does not reproduce the gesture to draw the spiral; compare this spectrogram with the ones in Figure 7.

By changing the mapping, we get different pitches (and relative durations), but, if our mapping follows the criterion of gestural similarity, the overall structure will be preserved. The upper spectrogram highlights details of the pitch contour (blue) of the beginning of the melody, with up-down movements and enlarging intervals and durations. The movement of fundamentals does not look like a spiral: it tracks the motion along the 2D-model. The listener recognizes the feeling of spiral-like movements in the space of musical parameters. Thus, spectrograms have to be understood in terms of gestural similarity and not simply considered as drawings.

This is the main difference between musical sequences derived from images, such as the ones obtained with Xenakis' UPIC tablet (Xenakis, 2001) or Aphex Twin's spiral-like spectrograms (Figure 8).

The analysis of spectrograms can be easy for legato/staccato (with visuals dots/lines) or vibrato/non-vibrato (with a visual straight line or a squiggly line) musical sequences, but it is not as simple for other examples. Nevertheless, the spirals in Vertigo's music are clear to the listeners! A criterion to investigate spectrograms should take into account human perception and movements within the music-parameter space. Multi-modal machine learning techniques may help find approximate similarity values.

\section{The Klein Concert and a mathematical ocean}

Creative applications of GSC led to music „derived“ from fish, gondolas, landscapes, and the Klein bottle. Musical compositions from the Klein bottle have been composed and performed by students of the Conservatory of Palermo during the „Klein Concert" in May 2019 (see Klein concert in the Web Sources). The event concluded one of the courses thought and taught by M. M., starting from Fall 2018 in Europe (Italy and the UK).

Let us now present Fish Math by M. M., a sort of mathematical ocean, whose components are graphs of parametric equations and revolution plots (Figure 9), whose progressive appearance is accompanied by simple musical sequences, improvised according to GSC (see Fish Math in the Web Sources). Some people asked M. M. about the algorithm used to simultaneously generate images and sounds: perhaps new experiments can start from short animations and more complete musical passages? 
Figures 10, 11, and 12 illustrate examples of the appearance of single forms in the video and the structure of the (improvised and then transcribed) music that accompanies them. A superficial reading of these applications can classify them as „arbitrary“. However, the degrees of freedom present in artistic realizations contribute to make the theoretical applications more living; e.g., Xenakis himself was starting from science and then making adjustments. Here, the choice of individual pitches and rhythms/harmonies may change, but overall, articulation, volume, and rough pitch contour are meant to evoke specific movements in the mind of the listeners, e.g., the gesture to draw a point (and to play a soft staccato) becomes the soft and fast creation of a sphere, seen from afar as a point, and musically as a soft staccato cluster.

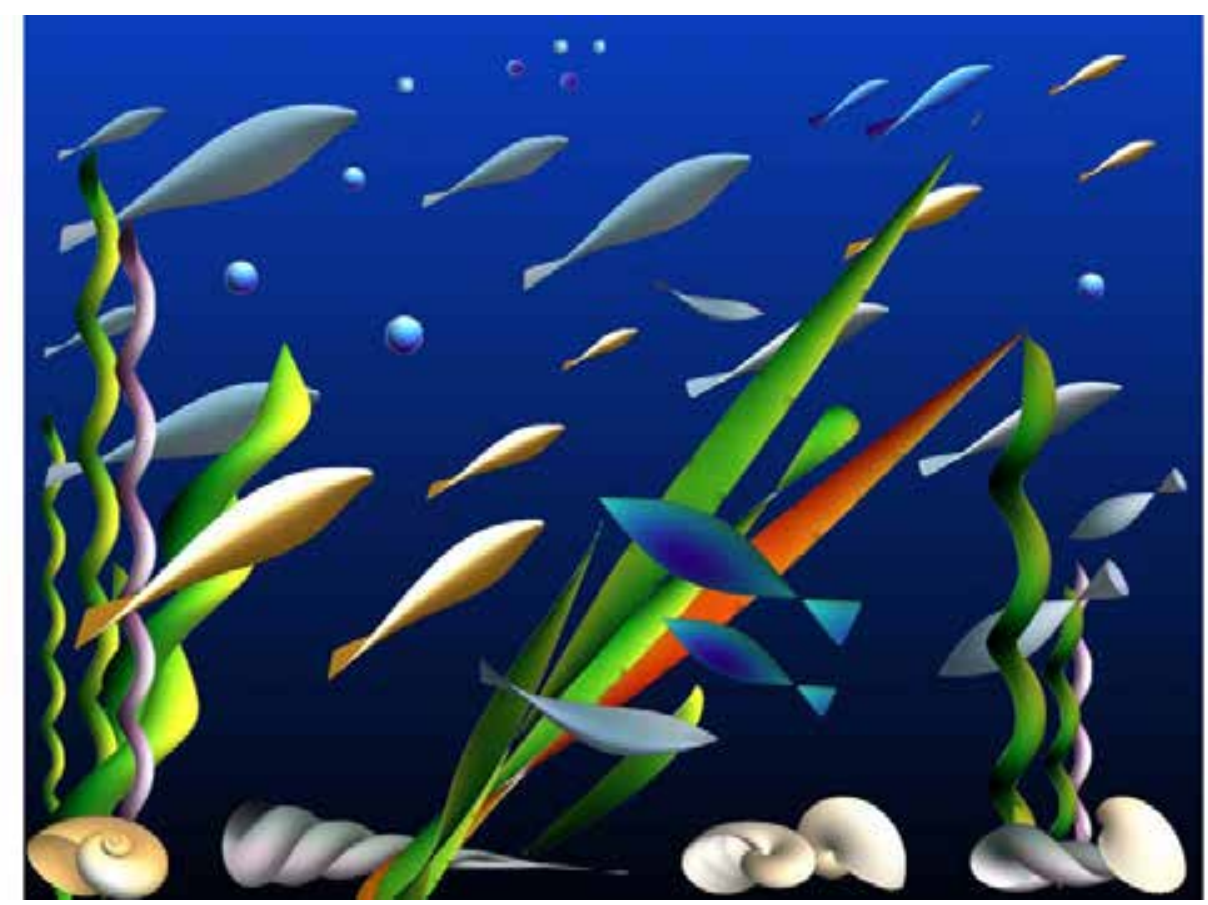

Figure 9. Fish Math. ${ }^{7}$ This is an image of a sort of „mathematical ocean“ where all images, produced with Mathematica software, are graphs of parametric equations and revolution plots. ${ }^{8}$

7 The image by Maria Mannone.

8 The image has been displayed at the Mathematical Art Gallery during the Joint Mathematics Meetings in Denver (January 2020). The link of a video with music that seems to be generated at the same time of images, according to GSC, is listed in the Web Sources. 


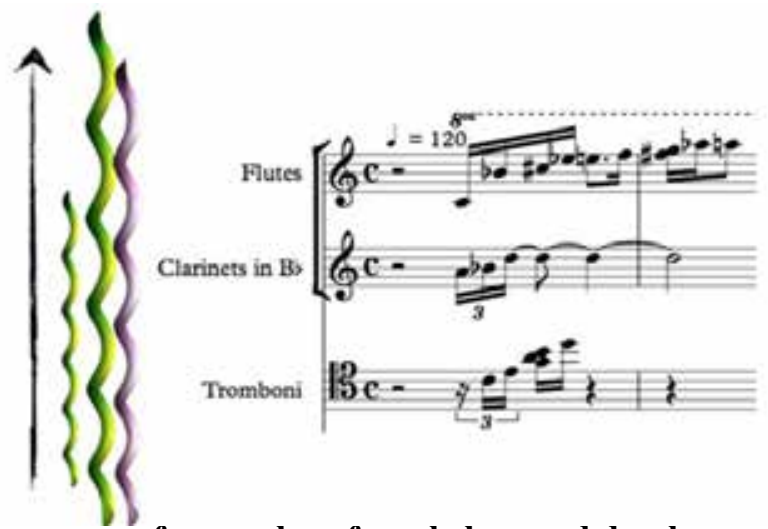

Figure 10. Appearance of some algae from below, and development of a musical phrase. Transcription from the improvised music. This movement of algaeappearing is quite fast in the video

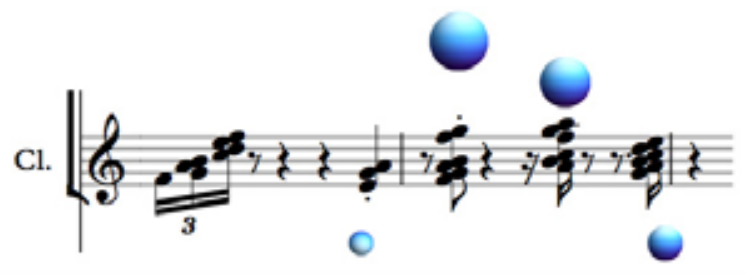

Figure 11. Spheres as air balls in the water that appear in the video as expanding from the center, and they are visible in some points as small dots.

They are musically rendered with soft staccato chords. (Timbre of clarinet, measures 6-7 of the transcription.)
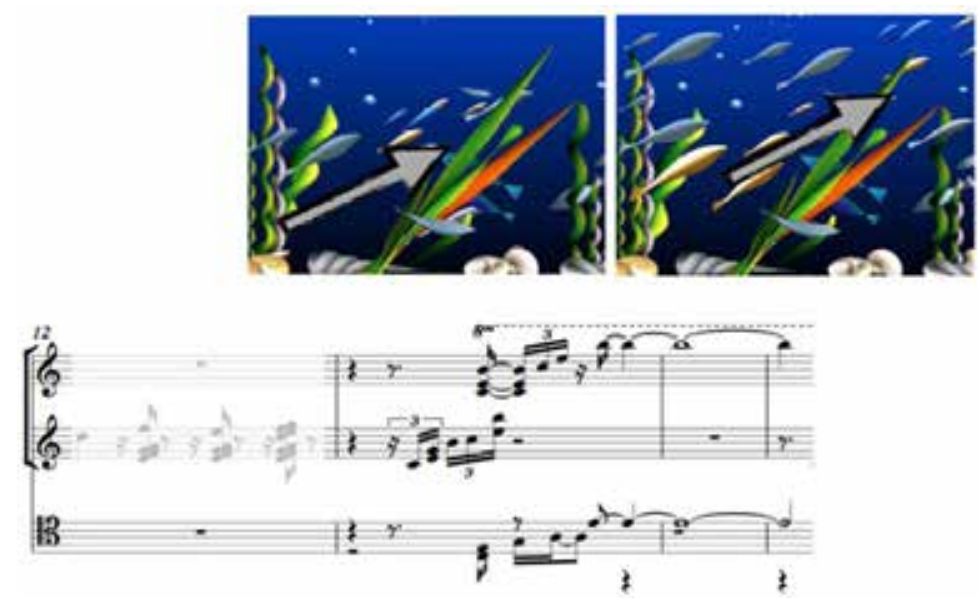

Figure 12. The appearance of a group of fish is rendered with chordal movement. The choice of harmony gives a feeling of calm and completeness. 


\section{Conclusions and Further Developments}

The experiment showed that there is a non-negligible correlation between characteristics of some simple shapes and characteristics of sound stimuli, according to GSC (Mannone, 2018). Other technical developments will include a computational analysis of the experiment outcomes, to more deeply investigate results and to more clearly prepare new future experiments.

Future experiments will involve more complex and detailed shapes as well as richer musical sequences, including polyphonies. The transition from simple, essential forms to more complex ones hearken back to Gestalt, with added challenges such as the recognizability of a form from the visual to the auditory domain. In general, we would say that this is not possible. But we can establish some conditions that make a sonification (or a visualization) „Gestalt-invariant“, retaining the essential information, involving a vocabulary of simple forms and a corresponding vocabulary of simple musical sequences. A complex visual form can be approximated via simple forms with coefficients. There will be a threshold value with a minimal number of elements to allow the original image recognizability. This approximation can be translated into sound: term by term, coefficient (where, how many, how big) by coefficient (how loud, when, how often, how high); see (Mannone et al., 2020).

The research on gestural similarity is still ongoing. The described experiment can be considered as an important step in this research process.

\section{Acknowledgments}

A heartfelt acknowledgment to Tom Collins (The University of York, UK) who, while at Lehigh University in the U.S., participated in the preliminary discussion, ran the experiment with his students, and analyzed the results. We also thank Delilah Hsu (Lehigh University alumna), who participated in the experiment preparation and in the analysis of the results. Without their contribution, the experimental side of this research would not have been possible. T. C. is collaborating for an article regarding the details of the cognitive analysis of this experiment (Mannone et al., 2018/20).

\section{REFERENCES:}

1. Arias, Juan Sebastian. 2018. „Spaces of gestures are function spaces.“ Journal of Mathematics and Music, 12 (2), 89-105.

2. Arias-Valero, Juan Sebastian, \& Luis-Puebla, Emilio. 2020. „Some remarks on hypergestural homology of spaces and its relation to classical homology." Journal of Mathematics and Music, https://www.tandfonline.com/doi/full/10.1080/17459737.2020.1722269.

3. Borgo, David. 2011. „Embodied Music Cognition and Mediation Technology.“ Literary and Linguistic Computing, 27 (1), 97-99. 
4. Clark, Timothy L. 2020. „On the topological characterization of gestures in a convenient category of spaces." Journal of Mathematics and Music, https:/www.tandfonline.com/doi/full/ $10.1080 / 17459737.2020 .1716403$.

5. Eitan, Zohar, \& Granot, Roni. 2006. „How music moves: Musical parameters and listeners' images of motion, Perceptual characterization of motion evoked by sounds for synthesis control purposes." Music Perception, 23 (3), 221-247

6. Eitan, Zohar, Onroy, Eitan, \& Granot, Roni. 2012. „Listening in the Dark: Congenital and early blindness and cross-domain mappings in music." Psychomusicology: Music, Mind, and Brain, $22(1), 33-45$

7. Engeln, Lars, \& Groh, Rainer. 2019. „CoHEARence: a qualitative User-(Pre-)Test on Resynthesized Shapes for coherent visual Sound Design." In: AM'19: Proceedings of the $14^{\text {th }}$ International Audio Mostly Conference: A Journey in Sound, September 2019, pp. 98-102.

8. Engeln, Lars, \& Groh, Rainer. 2020. „CoHEARence of audible shapes - a qualitative user study for coherent visual audio design with resynthesized shapes." Personal and Ubiquitous Computing, https://doi.org/10.1007/s00779-020-01392-5.

9. Fortuna, Sandra. 2017. „Embodiment, sound and visualization: A multimodal perspective in music education." In: Collected papers of the Academy of Arts./Zbornik radova Akademije umetnosti, Issue 5, pp. 120-131.

10. Godøy, Rolf Inge, Haga, Egil, \& Jensenius, Alexander R. 2006. „Playing ‘Air Instruments’: Mimicry of Sound-Producing Gestures by Novices and Experts." In: Gibet S., Courty N., Kamp J. F. (eds) Gesture in Human-Computer Interaction and Simulation. GW 2005. Lecture Notes in Computer Science, 3881, pp. 256-267. Berlin, Heidelberg: Springer.

11. Godøy, Rolf Inge, \& Leman, Marc (eds.). 2010. Musical Gestures: Sound, Movement, and Meaning. New York: Routledge.

12. Jedrzejewski, Franck. 2019. Hétérotopies musicales. Paris: Hermann.

13. Jensenius, Alexander R., Wanderley, Marcelo M., Godøy, Rolf I., \& Leman, Marc. „Musical Gestures: concepts and methods in research.“ In: R. I. Godøy \& M. Leman (eds.), Musical gestures: Sound, movement, and meaning (pp. 12-35). New York: Routledge.

14. Kelkar, Tejaswinee, \& Jensenius, Alexandre R. 2018. „Analyzing Free-Hand Sound-Tracings of Melodic Phrases.“ Applied Sciences, 8 (135), 1-21.

15. Kozak, Mariusz. 2020. Enacting Musical Time: The Bodily Experience of New Music, Chapter 3. New York: Oxford University Press.

16. Kubovy, Michael, \& Schutz, Michael. 2010. "Audio-visual objects." Review of Philosophy and Psychology, 1 (1): 41-61.

17. Leech-Wilkinson, Daniel, \& Prior, Helen M. (eds.). 2017. Music and Shape, Studies in Musical Performance as Creative Practice. New York: Oxford University Press.

18. Leman, Marc. 2008. Embodied Music Cognition and Mediation Technology. Cambridge, Massachusetts: MIT Press.

19. Leman, Marc. 2016. The Expressive Moment: How Interaction (with Music) Shapes Human Empowerment. Cambridge, Massachusetts: MIT Press.

20. Martolini, Chiara, Cappagli, Giulia, Campus, Claudio, and Gori, Monica. 2019. „Shape Recognition With Sounds: Improvement in Sighted Individuals After Audio-Motor Training.“ Multisensory Research, 33 (4-5), pp. 417-431.

21. Mac Lane, Saunders. 1978. Categories for the Working Mathematician. New York: Springer.

22. Mannone, Maria. 2011. Dalla Musica all'Immagine, dall'Immagine alla Musica. Palermo: Compostampa. 
23. Mannone, Maria, Papageorgiou, Dimitri, \& Collins, Tom 2018/2020. „Psychological validation of the Mathematical Theory of Musical Gestures." Submitted.

24. Mannone, Maria, Favali, Federico, Di Donato, Balandino, \& Turchet, Luca. 2020. „Quantum GestART. Identifying and Applying Correlations between Mathematics, Art, and Perceptual Organization.“ Journal of Mathematics and Music, https://doi.org/10.1080/17459737.2020.172 $\underline{6691}$.

25. Mannone, Maria. 2019. Mathematics, Nature, Art. Palermo: Palermo University Press.

26. Mannone, Maria. 2018. „Introduction to Gestural Similarity. An application of Category Theory to the Orchestra." Journal of Mathematics and Music, 12 (2), 63-87.

27. Mazzola, Guerino, \& Andreatta, Moreno. 2007. „Diagrams, gestures and formulae in music.“ Journal of Mathematics and Music, 1 (1), 23-46.

28. Niewiadomski, Radoslaw, Mancini, Maurizio, Cera, Andrea, Piana, Stefano, Canepa, Corrado, Camurri, Antonio. 2018. „Does embodied training improve the recognition of mid-level expressive movement qualities sonification?“, Journal on Multimodal User Interfaces, https:// doi.org/10.1007/s12193-018-0284-0.

29. Niinisalo, Jarmo. 2017. „The Aphex Face“ (blogpost). http://www.bastwood.com/?page id=10.

30. Rosenblum, Lawrence D., Dias, James W., \& Dorsi, Josh. 2016. „The supramodal brain: implications for auditory perception.“ Journal of Cognitive Psychology, 29 (1), 65-87.

31. Repp, Bruno. 1992. „Music as Motion: A Synopsis of Alexander Truslit’s (1938).“ In: Gestaltung und Bewegung in der Musik. Haskins Laboratories Status Report on Speech Research, SR-111/112, pp. 265-278.

32. Spence, Charles. 2011. Crossmodal Correspondences: A Tutorial Review. Attention, Perception and Psychophysics, 73: 971-995.

33. Xenakis, I. 2001. Formalized Music. New York: Pendragon.

34. Zbikowski, Lawrence. 2017. „Music, Analogy, and Metaphor.“ Chapter in: The Routledge Companion to Music Cognition, edited by R. Ashley and R. Timmers. 501-512. New York: Routledge.

\section{WEB SOURCES:}

1. Perfect Shapes in the Prehistoric Sea: https://soundcloud.com/maria-mannone/perfect-shapesin-the-prehistoric-sea-2018

2. Fish Math: https://www.youtube.com/watch?v=4M5qRz5fxVE

3. Klein Concert: https://www.youtube.com/watch?v=6Bn8PyZbsJc

\section{Gestovna sličnost, matematika, psihologija: nagoveštaji nakon prvog eksperimenta i neke primene između pedagogije $i$ istraživanja}

Apstrakt: Da li se muzika i crteži mogu smatrati rezultatima fizičkih gestova, te se na taj način mogu uporediti? U ovom radu će se sumirati hipoteza o ,gestovnoj sličnosti“ koja je razvijena u okviru matematičke teorije o muzičkim gestovima. Zatim će se izložiti istorija eksperimenta koji uključuje matematiku, muziku, crtanje i psihologiju, sa ciljem da se proceni kognitivna relevantnost hipoteze. Jednostavna vizuelna forma $i$ 
kratki homofoni muzički niz mogu se smatrati „sličnim“ ako se mogu zamisliti kao da su proizašli iz istih pokreta. Učesnici u eksperimentu su zamoljeni da procene stepen sličnosti između datih muzičkih primera i jednostavnih vizuelnih prikaza (tri prikaza za svaki muzički stimulus). Analizom rezultata potvrđena su teorijska očekivanja. Pored toga, rad opisuje neke kreativne primene ove hipoteze, uključujući pedagoški i kreativni razvoj. Konkretno, opisuje se muzika koja je izvedena iz prirodnog oblika, suštinske strukture amonita i iluzije „matematičkog okeana“ sa zvukovima i slikama. Razmatraju se izazovi ovih tehnika i karakteristike spektrograma u odnosu na gestovnu sličnost.

Ključne reči: muzička artikulacija, pokret, gest, crtanje, percepcija. 